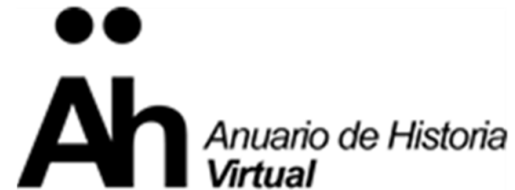

\section{Clase y género en la Córdoba combativa. Las obreras de ILASA y la ocupación de la fábrica en 1970}

\author{
[Class and Gender in Militant Córdoba. \\ The Woman Workers of ILASA and the Factory Occupation in 1970] \\ Rodolfo Laufer \\ (Consejo Nacional de Investigaciones Científicas y Técnicas \\ - Universidad de Buenos Aires - Instituto Ravignani) \\ rodolfo.laufer@yahoo.com.ar
}

\section{Resumen:}

El ciclo de movilización y radicalización política del movimiento obrero cordobés de los años 60 y 70 ha sido objeto de múltiples indagaciones, pero no existen estudios que lo hayan abordado desde una perspectiva que articule las variables de clase y género. En este artículo reconstruimos la experiencia laboral y sindical de las obreras de la fábrica de componentes automotrices ILASA, pertenecientes al sindicato SMATA: analizamos los rasgos de la empresa y su composición obrera, el activismo sindical y político en la planta, el impacto del Cordobazo y, particularmente, la participación de sus trabajadoras en el plan de ocupaciones fabriles llevado a cabo por el sindicato mecánico en 1970. Así, mostramos cómo sus condiciones de sobreexplotación, su incorporación a la clase obrera organizada y la radicalización política general tornaron a las obreras de ILASA en protagonistas centrales del cambio de estrategias sindicales que llevaría a la experiencia del clasismo en el SMATA Córdoba.

Palabras clave: ILASA - Córdoba - Género SMATA - Clasismo.

\begin{abstract}
:
The cycle of mobilization and political radicalization of the Córdoba labor move-ment during the 60 s and 70s has been the subject of multiple investigations, but there are no studies that have analyzed it with a perspective that combines class and gen-der. In this paper we reconstruct the experience of the women employed in the au-tomotive components factory ILASA, which belonged to the SMATA union: we ana-lyze the characteristics of the company and its worker composition, the union and political activism in the plant, the impact of Cordobazo and, especially, her partici-pation in the factory occupations plan carried out in 1970. In this way, we show how their conditions of overexploitation, their entry into the organized working class and the political radicalization made the women workers of ILASA key protagonists of the change in union strategies that would lead to the experience of clasismo in SMATA Córdoba.
\end{abstract}

Keywords: ILASA - Córdoba - Gender - SMATA - Clasismo.

Recibido: 24/09/2019

Evaluación: 16/10/2019

Aceptado: 15/11/2019

Anuario de la Escuela de Historia Virtual - Año 10 - N 16 - 2019: pp. 93-114.

ISSN: 1853-7049

http://revistas.unc.edu.ar/index.php/anuariohistoria 


\section{Clase y género en la Córdoba combativa. Las obreras de ILASA y la ocupación de la fábrica en $1970^{1}$}

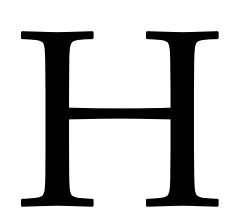
acia fines de los años 60 e inicios de los 70, el movimiento obrero de Córdoba fue escenario de un intenso proceso de radicalización sindical y política, cuya punta de lanza la constituyeron los trabajadores automotrices, el corazón de la industria local. En 1970, mientras se desarrollaba la experiencia clasista en las plantas de Fiat Concord y Materfer, ${ }^{2}$ crecía también una alternativa opositora liderada por referentes clasistas en el Sindicato de Mecánicos y Afines del Transporte Automotor (SMATA), que representaba a los trabajadores de las plantas Santa Isabel, Perdriel e ILASA de IKA-Renault, Grandes Motores Diesel de Fiat, Transax de Ford y Thompson Ramco. En junio de 1970, los mecánicos llevaron a cabo una oleada de ocupaciones fabriles con rehenes que conmovieron la ciudad y significaron un punto de quiebre en las dinámicas de acción sindical del SMATA. En las siguientes elecciones sindicales, en abril de 1972, la antigua conducción sindical peronista vandorista de Elpidio Torres sería reemplazada por la Lista Marrón, encabezada por René Salamanca.

Este ciclo de movilización y radicalización obrera ha sido objeto de múltiples investigaciones, inscriptas en diversas perspectivas historiográficas (Brennan, 1996; Gordillo, 1996; Brennan y Gordillo, 2008; Mignon, 2014; Ortiz, 2015; Laufer, 2017), pero prácticamente no existen estudios que lo hayan abordado mediante un enfoque que articule las variables de clase y género. ${ }^{3}$ Esto incluye, desde ya, nuestras propias producciones hasta el momento. Así, se puede decir que la historia del resonante movimiento obrero cordobés en este período ha sido una historia esencialmente masculinizada. Si este señalamiento vale para el análisis del conjunto de esta experiencia sindical y de clase, resulta especialmente pertinente dada la peculiar presencia en la rama automotriz de una fábrica cuya composición era mayoritariamente femenina: ILASA (Industria Latinoamericana de Accesorios S.A.), caso paradigmático de la incorporación de las mujeres al

\footnotetext{
${ }^{1}$ Una primera versión de este trabajo fue presentada como ponencia en las Jornadas "A 50 años del Cordobazo. Repensando el ciclo de protestas obreras, rebeliones populares e insurrecciones urbanas", realizadas en la ciudad de Córdoba el 24 y 25 de mayo de 2019.

2 Se conoce así a la experiencia desarrollada por los trabajadores de estas dos plantas de Fiat y sus sindicatos SITRAC y SITRAM entre marzo de 1970 y octubre de 1971, marcada por la defenestración de las conducciones sindicales "amarillas", el ascenso de nuevos dirigentes que se identificaron como "clasistas" y una práctica sindical fuertemente democrática, combativa y políticamente radicalizada.

${ }^{3}$ El primer trabajo que incorporó la dimensión de género al estudio del movimiento obrero cordobés de este período fue el de Paola Floresta (2012) sobre el sindicalismo docente. Cabe mencionar que actualmente están en curso una serie de investigaciones que se proponen avanzar en este sentido, como las de Ana Noguera (2019) y el proyecto de tesis doctoral de Paula Romani, dedicada al estudio de "La familia y la configuración de una identidad de clase en la Córdoba obrera (1952-1976)".
} 
mundo fabril provincial y uno de los más tempranos núcleos de oposición a la conducción del SMATA que lideraba Torres.

Las elaboraciones de la historia social británica de los años 60 y el desarrollo de la llamada segunda ola del movimiento feminista en los 60 y 70 constituyeron un impulso para la ampliación de las perspectivas analíticas acerca de la historia de la clase obrera, dentro de la cual comenzaron a abrirse paso una serie de estudios con centro en la articulación entre la condición de clase y el género. Esto, que en una primera etapa permitió comenzar a superar la invisibilización de las mujeres, incorporándolas al relato histórico sobre la clase obrera, se profundizó luego a partir del desarrollo de preguntas y distintas interpretaciones acerca del significado de los sexos y el concepto de género (Kelly Gadol, 1976; Scott, 1993; Bock, 1989; Hall, 2013). La introducción del género replanteó los términos del debate y la indagación histórica: el problema ya no era solamente restituir la presencia de las mujeres en la historia, sino analizar las construcciones sociales y culturales sobre los géneros, sus relaciones e identidades, los lugares ocupados y los roles asignados. De este modo, tomar al género como una dimensión constitutiva de las posiciones, las relaciones y la experiencia de clase, adoptando una perspectiva de clase generizada, abrió nuevos interrogantes acerca de los trabajos ligados al ámbito de la reproducción social, las particularidades de la incorporación de la mujer al mundo fabril capitalista, las representaciones de feminidad y masculinidad entre los trabajadores, o la manera en que las construcciones de género influyen en las formas de organización y lucha obrera.

Como sostuvo Eric Hobsbawm, las décadas posteriores a la Segunda Guerra Mundial fueron testigos a nivel mundial de una serie de profundas transformaciones sociales y culturales que, en cuanto a las mujeres, significaron una ampliación de su incorporación al mundo laboral y a la educación universitaria, un aumento de su participación social y política y una serie de cambios en las pautas familiares y sexuales (Hobsbawm, 2007). A su vez, esto se combinó con un ascenso revolucionario mundial, con rasgos antiimperialistas y anticapitalistas y un cuestionamiento generalizado al status quo, protagonizado por la clase obrera, los estudiantes, las minorías raciales, las naciones oprimidas y en general por la juventud, lo cual alentó también el surgimiento de organizaciones políticas de una nueva izquierda revolucionaria. En la Argentina, efectivamente, la década del 60 presenció un importante crecimiento del empleo femenino, centralmente en las zonas urbanas y concentrado principalmente en los sectores de comercio y servicios (Recchini de Lattes, 1980). ${ }^{4}$ Por su parte, Isabella Cosse (2009) señala que, en estos años, el prototipo femenino de la "mujer doméstica" (casada y dedicada totalmente a la familia, el hogar y los hijos) comenzó a ceder terreno frente a lo que denomina la "joven liberada" (económicamente independiente, liberada sexualmente y capaz de realizarse

\footnotetext{
${ }^{4}$ Según los datos censales, en 1974 solo el 9\% del personal remunerado en el sector industrial estaba constituido por mujeres. Censo Nacional Económico 1974, Total del País, Industria, Resultados definitivos. Instituto Nacional de Estadísticas y Censos (INDEC), Ministerio de Economía, Hacienda y Finanzas, República Argentina. Disponible en: https://biblioteca.indec.gob.ar/bases/minde/1c1974_1.pdf. Descarga: 27/3/19.
} 
fuera del hogar), un proceso que tuvo su foco en las capas medias y altas. Córdoba no fue ajena a estos procesos, como lo muestra el hecho de que en 1967 la Universidad local organizara un Curso de Temporada dedicado a "La mujer argentina y latinoamericana", en donde fueron presentados varios trabajos que daban cuenta de los cambios en la posición de la mujer, entre ellos su creciente inserción en el mercado de trabajo y las tensiones que esto generaba con los modelos tradicionales. ${ }^{5}$

Como ha sido señalado por Andrea Andújar (2017), Débora D’Antonio y Cristina Viano (2017), los trabajos que han utilizado la perspectiva de género para incursionar en la Argentina de los 60 y 70 se han enfocado principalmente en sujetos y tópicos como la militancia política, la represión y las transformaciones en la familia y la sexualidad, y son aún pocos e incipientes los centrados en la clase trabajadora y el ámbito sindical. ${ }^{6}$ Tal como señalamos anteriormente, esto vale especialmente para Córdoba, donde la problematización de las cuestiones de género puede encontrarse principalmente en publicaciones dedicadas a la militancia social y política (AAVV, 2006; Noguera, 2013 y 2019; Noguera, 2019; Fulchieri, 2018).

A partir de las reflexiones anteriores, en este artículo nos proponemos dar un primer paso en la reconstrucción y el análisis de la experiencia laboral y sindical de las trabajadoras de ILASA desde una perspectiva de clase generizada. Lo hacemos como parte de una investigación más general, que tiene como eje el estudio de la experiencia sindical de los trabajadores del SMATA cordobés bajo el período dictatorial de la "Revolución Argentina" (1966-1973) y la gestación y desarrollo de los agrupamientos opositores y clasistas que terminaron por conquistar la conducción sindical en 1972.7 Para ello, iniciaremos reponiendo las características de la industria automotriz y la inserción laboral femenina en la provincia, los rasgos de la empresa ILASA, su composición obrera, sus condiciones de trabajo y su organización gremial en el marco del SMATA. Tras ello, reconstruiremos el activismo sindical y político en la planta, el impacto del Cordobazo y la radicalización del movimiento obrero provincial y analizaremos específicamente la participación de las obreras de ILASA en el plan de lucha con ocupaciones fabriles del SMATA Córdoba llevado a cabo en junio y julio de 1970. Finalmente, ofreceremos algunas reflexiones acerca de la participación de las obreras mecánicas en el proceso de radicalización sindical y política que transformó a Córdoba en la provincia más convulsionada de la Argentina.

\footnotetext{
${ }^{5}$ Entre los trabajos presentados, son particularmente pertinentes los dos elaborados por la cordobesa Eva Chamorro Greca (1969a; 1969b), titulados “La mujer en la estructura familiar" y "La madre que sale a trabajar", realizados en base a su trabajo de campo en la propia Córdoba. Allí, la autora sostuvo que se estaba produciendo un cambio en el estatus de los distintos miembros de la familia, que tenía como sujeto principal a la mujer y se debía esencialmente a sus nuevas posiciones ocupacionales.

${ }^{6}$ Entre otros, Rodríguez (2010), Barragán (2014; 2015), Mitidieri (2014), Ghigliani (2018) y Lenguita (2018).

${ }^{7}$ Nuestra investigación se enmarca en el Doctorado en Historia de la Facultad de Filosofía y Letras de la Universidad de Buenos Aires (FFyL-UBA) y cuenta con el apoyo de una Beca Doctoral del Consejo Nacional de Investigaciones Científicas y Técnicas (CONICET).
} 
Las fuentes relevadas combinan documentos escritos con testimonios de protagonistas. Entre las primeras se cuentan diarios y periódicos provinciales, documentos sindicales, empresariales y estatales, y materiales de las organizaciones políticas de la izquierda marxista y peronista. En cuanto a las fuentes orales, utilizamos entrevistas a obreras, activistas y delegadas de ILASA que tuvieron un rol destacado en el proceso. Las imágenes incluidas en el artículo fueron obtenidas de periódicos provinciales, revistas de difusión de la empresa IKA y noticieros televisivos de la época. ${ }^{8}$

\section{Ser obreras en ILASA}

Cuando nació ILASA en 1964, la ciudad de Córdoba constituía ya la segunda concentración de trabajadores industriales del país, con un crecimiento cimentado en la producción automotriz. Esta reconocía sus inicios en las Industrias Aeronáuticas y Mecánicas del Estado (IAME), pero su salto se produjo a mediados de los 50 a partir de la radicación de las empresas extranjeras Fiat (italiana) e Industrias Kaiser Argentina (IKA, norteamericana). A partir de entonces, la ciudad mediterránea absorbió grandes cantidades de mano de obra e impulsó el desarrollo de una miríada de industrias subsidiarias de componentes, repuestos y accesorios automotrices.

\section{Imagen 1. La planta de ILASA}

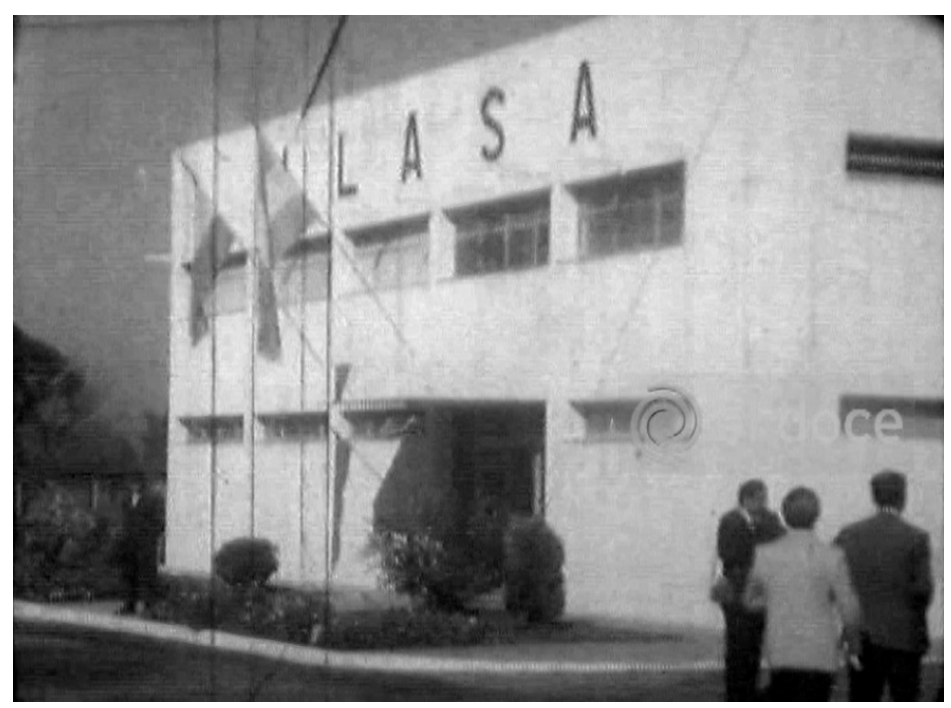

Fuente: CDA-Archivo Fílmico-UNC. Canal 12. Derechos amparados por Ley 11.723.

\footnotetext{
${ }^{8}$ Los materiales audiovisuales de la época han sido preservados y puestos a disposición pública gracias a la labor del Centro de Conservación y Documentación Audiovisual (CDA) de la Universidad Nacional de Córdoba (UNC). URL: https://ffyh.unc.edu.ar/cda/.
} 
Según datos de 1974, solo el 11\% de la mano de obra industrial de toda la provincia era femenina, y el único sector en el que predominaban las mujeres era el de "Textiles, prendas de vestir e industria del cuero". ${ }^{9}$ La "Fabricación de vehículos automotores" con 20.399 trabajadores remunerados, ocupaba solo un $4 \%$ de mujeres (828). Pero, si enfocamos específicamente a la "Fabricación de componentes, repuestos y accesorios para automotores", con 6.894 ocupados, el personal femenino ascendía a un 6\% (423). Las responsables de este incremento estadístico eran justamente las obreras de ILASA.

En cuanto a la ciudad de Córdoba, un informe realizado en 1972 indicaba que del total de 427.696 mujeres que vivían allí, solo 113.538 (26,5\%) integraban la Población Económicamente Activa (PEA). De estas, el 78,32\% se hallaba empleada en actividades de servicios (educación, comercio, servicio doméstico y salud), mientras que "la participación femenina en la ocupación industrial solo tiene relevancia en la industria textil y de confecciones". A su vez, señalaba que las mujeres se encontraban en una situación de inferioridad tanto en términos de condiciones de trabajo, "pues la proporción de hombres en tareas calificadas y de nivel técnico, directivo o profesional es muy superior a la proporción femenina de las mismas", como en cuanto a los índices de desocupación, ya que "la mujer es la última en ser empleada y la primera en ser despedida según sea expansiva o depresiva la coyuntura económica" (Baracat, 1974, p. 4).

La Industria Latinoamericana de Accesorios S.A. fue creada producto de la iniciativa de IKA en asociación con la también norteamericana Lockheed (McCloud, 2015, pp. 222223; Cipolla, 2004, pp. 97-98). ${ }^{10}$ Ubicada al norte de la ciudad, sobre la ruta al Aeropuerto de Pajas Blancas, su finalidad era la producción de mazos de cables para la instalación eléctrica, carburadores "Carter", bombas de combustible y materiales de fundición destinados a los vehículos producidos por IKA y otras firmas automotrices. A diferencia del resto de las empresas de la rama, donde las pocas mujeres que trabajaban lo hacían como empleadas administrativas, la mayoría del personal de ILASA, de entre 300 y 400 personas según el período, estaba compuesto por obreras mujeres, dedicadas a tareas de producción en las distintas secciones de elaboración de cables. Junto a ellas trabajaban unas cuantas decenas o una centena de obreros, ubicados en las áreas de fundición, carburadores y mantenimiento. De este modo, la organización laboral evidenciaba de por sí una división de tareas basada en supuestos generizados: a las mujeres se les asignaban tareas manuales simples y repetitivas, que requerían "delicadeza" y motricidad fina, coordinación, buena vista y concentración, pero que no precisaban calificación o una experiencia previa, mientras que los hombres eran destinados a tareas que requerían mayor esfuerzo y fuerza física, o una calificación y experiencia. Por esa razón, muchos de los obreros

\footnotetext{
${ }^{9}$ Censo Nacional Económico 1974, Córdoba, Industria, Resultados definitivos. Dirección de Informática, Estadística y Censos de Córdoba. Instituto Nacional de Estadísticas y Censos (INDEC), Ministerio de Economía, Hacienda y Finanzas, República Argentina. Disponible en: https://biblioteca.indec.gob.ar/cgi-bin/wxis.exe/bases/minde/c1974_x8_4.pdf. Descarga: 27/3/19.

${ }^{10}$ Memoria y Balance al 30 de junio de 1964, Industrias Kaiser Argentina S.A., p. 6. IKA, 10 años: 1955-1965, División Relaciones Públicas de Industrias Kaiser Argentina, Buenos Aires, 1965, p. 124.
} 
varones provenían de la planta principal de IKA. Sobre esta base, las obreras tenían siempre las categorías más bajas, lo que implicaba un salario menor que el de los varones de la misma fábrica. ${ }^{11}$ En el mismo sentido, también el personal jerárquico era totalmente masculino, aunque los supervisores tenían la potestad de designar una "líder" en cada sección según su preferencia, lo que, según los testimonios, siempre se dirigía a las más condescendientes con la patronal. La jornada laboral se dividía en tres turnos, pero, debido a las disposiciones vigentes, las mujeres no trabajaban en el horario nocturno.

\section{Imagen 2. Obrera trabajando en ILASA}

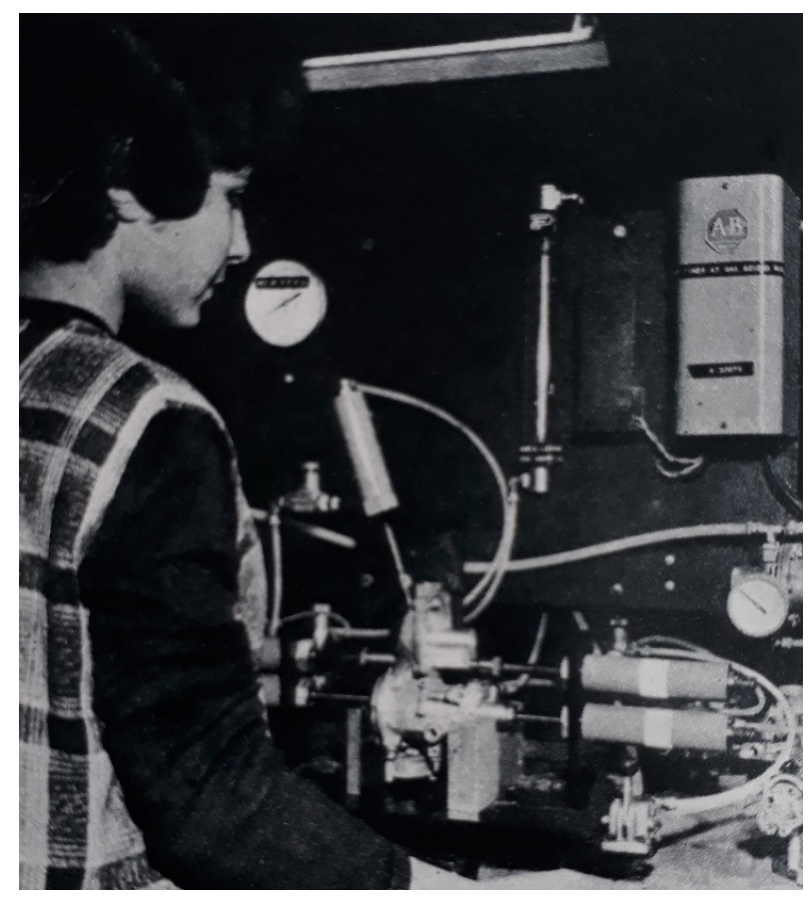

Fuente: IKA, 10 años: 1955-1965, División Relaciones Públicas de Industrias Kaiser Argentina, Buenos Aires, 1965, p. 124.

Las obreras que contrató ILASA, al menos en su primera etapa, eran en su mayoría muy jóvenes, con edades que oscilaban entre los 16 y los 25 años, y siempre solteras. De ese modo, su incorporación al mercado laboral en general no se debía a la necesidad de complementar el salario de un marido, como en otros casos, sino que su fin era contribuir al mantenimiento de su familia, o incluso comenzar a poner los cimientos de una independencia económica y una vida social más amplia. ${ }^{12}$ Nidia, por ejemplo, ingresó a la

\footnotetext{
${ }^{11}$ En este punto, cabe señalar además que para las obreras de ILASA las posibilidades de obtener una formación técnica que les permitiera elevar su calificación profesional en las áreas de mecánica, matricería, electricidad o fundición eran prácticamente inexistentes.

${ }^{12}$ El mencionado trabajo de Chamorro Greca, si bien está basado en noventa entrevistas a madres de familia cordobesas con diferentes trabajos extra-hogareños en los que solo una minoría eran obreras fabriles, con-
} 
planta en 1964, con 19 años, por la necesidad económica de su familia: sus dos hermanas y su hermano ya se habían casado y ella había quedado como el único sostén de sus padres. ${ }^{13}$ Ana María, que entró en 1970, con 24 años, era hija única y su padre tenía un trabajo estable, por lo que, después de pasar por varios trabajos en oficinas y comercio, encontró en ILASA un trabajo en el que ganaba bien y le permitía realizar estudios u otras actividades por la tarde. ${ }^{14}$ Según los testimonios, cuando en los años siguientes las obreras comenzaban a formar pareja y tener hijos, la mayoría no dejaba el trabajo en la empresa, pero esto las ubicaba en la situación de cumplir una "doble jornada", ocupándose también de las tareas domésticas en sus hogares. ${ }^{15}$

Como muestran las mencionadas estadísticas, la incorporación de una joven cordobesa al mundo fabril automotriz era algo muy poco común en la época, por lo que estas trabajadoras se encontraban ya de por sí en una posición peculiar y en tensión con los mandatos tradicionales de género de la sociedad local. Varias entrevistadas señalan que muchas de sus hermanas o amigas, ya casadas y con hijos, solían verlas como "distintas" y "rebeldes", lo cual se fue atizando en la medida en que su incorporación a la colectividad obrera mecánica las sumó a la acción sindical, con sus asambleas, paros y movilizaciones callejeras.

Durante su primer año de funcionamiento, la empresa no contaba con vestuarios ni medidas de protección, y el personal incluso tenía que comer a campo abierto. En estas condiciones, y dada la juventud e inexperiencia de las nuevas obreras, fueron los obreros provenientes de IKA, junto a algunas pocas mujeres, las que promovieron la afiliación al SMATA, que se concretó en 1965. Así, se firmó el primer Convenio Colectivo de Trabajo (CCT) específico de la empresa, que permitió mejorar las condiciones de trabajo iniciales, pero, al mismo tiempo, sancionó una marcada desigualdad frente a los trabajadores empleados directamente por IKA, quienes cobraban significativamente más de lo que establecía el convenio de ILASA. Por otra parte, persistieron una serie de problemas que afectaban específicamente a las obreras, como el hecho de que tenían que trabajar permanentemente de pie, las restricciones para el uso del baño, para lo cual las

signaba también esta doble motivación: “La mujer no sólo trabaja fuera del hogar por necesidades económicas sino porque ello le permite ejercer otras actividades, que no las realizan aquellas mujeres que sólo se dedican al hogar" (1969b, p. 244).

${ }^{13}$ Entrevista del autor a Nidia M. Terragni, Córdoba, 17/03/2019. Nidia entró a ILASA en 1964, fue delegada durante el período de conducción de la Lista Marrón y posteriormente miembro de la Comisión Directiva del SMATA por dicha lista en 1974.

${ }^{14}$ Entrevista del autor a Ana María Rodríguez, Córdoba, 13-3-2019. Ana María entró a ILASA a mediados de 1970 y fue delegada y coordinadora de la Comisión Interna de ILASA durante el período de conducción de la Lista Marrón.

${ }^{15}$ Según Chamorro Greca, esto era lo acostumbrado en todos los casos de mujeres que tenían una familia y a su vez trabajaban: "Si bien el trabajo extra hogareño reporta ventajas materiales y satisfacciones o insatisfacciones espirituales para la mujer, ello no la libera de la realización de las tareas domésticas" (1969b, p. 254). De allí, la preocupación sociológica central que planteaba el trabajo de la autora: lo que caracterizó como el "doble peso" o la "doble expectativa" que sentía sobre sí la mujer, "la que corresponde a su rol de esposa y madre y la que le cabe como trabajadora" (Chamorro Greca, 1969a, p. 233). 
obligaban a solicitar un pase e impedían que hubiera más de tres en simultáneo, o la falta de una guardería para las que iban siendo madres.

Hasta la llegada de las obreras de ILASA, el SMATA era un mundo con una composición totalmente masculina, pero, además, particularmente masculinizado: dentro y fuera de las fábricas, los automóviles siempre habían sido "cosa de hombres". ${ }^{16}$ Desde 1958 el sindicato estaba bajo la conducción de Elpidio Torres, un dirigente peronista que, debido a su estrategia sindical que combinaba la movilización obrera y la negociación con las patronales al estilo del dirigente nacional del sindicato metalúrgico, era apodado "el Vandor cordobés". El discurso sindical casi siempre excluía a las trabajadoras de ILASA, hablando de "los obreros" o "los afiliados", y reproducía una imagen tradicional y doméstica de la mujer. ${ }^{17}$ De este modo, la incorporación de este contingente femenino planteó desde el inicio una tensión en la organización sindical mecánica.

\section{Las activistas obreras y la toma de ILASA}

La experiencia sindical de las trabajadoras de ILASA hasta 1970 estuvo marcada por la figura de Edith Vera. Nacida en 1943 y detenida-desaparecida en 1976, esta entró a la nueva planta junto con su hermana Gladys como parte de las primeras camadas de obreras contratadas, y al poco tiempo ambas fueron electas por sus compañeras como delegadas. Según el relato de Gladys, la trayectoria política de ambas estuvo marcada particularmente por un tío que era obrero de la construcción y militante del Partido Comunista (PC), José Menelao Páez: a partir de él conocieron y se vincularon de muy jóvenes a la militancia comunista de Córdoba y adquirieron sus primeros conocimientos de marxismo. Pero, una vez en ILASA, se integrarían a una nueva organización: la Agrupación "18 de marzo", liderada por Atilio Vidal Carnero y Héctor Maydana, de IKA, y ubicada dentro del espectro peronista en vías de radicalización.

"Pensábamos que estábamos más cerca de la gente militando en la izquierda pero en el peronismo. Porque como que el PC era muy chiquito, y si sabían que eras PC más o menos salían disparando, la gente tenía miedo. No fue algo ideológico, era algo que nos convenía a nosotras para sobrevivir. Si en la fábrica se enteraban que estabas con el comunismo te echaban". ${ }^{18}$

\footnotetext{
${ }^{16}$ Sobre la construcción de la masculinidad entre los trabajadores fabriles, su relación con la consolidación de la disciplina laboral y el reforzamiento de la explotación, así como su puesta en tensión durante los procesos de organización y lucha colectiva, ver: Rodríguez (2010), Barragán y Rodríguez (2013) y Palermo (2015).

17 En 1971, por ejemplo, el SMATA organizó un festival para festejar el “Día de la Madre” en el que para las "señoras y señoritas presentes" se sortearon artefactos hogareños (batidoras, licuadoras, juegos de cocina, planchas, etc.), al tiempo que se premió a la madre de más edad y a la esposa más joven de un afiliado y se inauguró un "Monumento a la Madre". SMATA Córdoba, Órgano del Sindicato de Mecánicos y Afines del Transporte Automotor Seccional Córdoba, № 65, 15/10/1971.

${ }^{18}$ Entrevista del autor a Gladys Vera, Córdoba, 15/08/2015.
} 
La "18 de marzo" era una agrupación del peronismo de izquierda, e integraba la Lista Blanca del SMATA, que se presentó como oposición a Elpidio Torres en 1964, 1966 y 1968. ${ }^{19}$ En 1966, Edith Vera integró la lista como Pro Secretaria de Actas, siendo la única mujer entre los 72 miembros de las cuatro listas que se presentaron. ${ }^{20} \mathrm{~A}$ nivel provincial, la agrupación estaba ligada al Peronismo de Acción Revolucionaria (PAR), uno de los eslabones perdidos de la izquierda peronista en Córdoba, encabezado por Marcelo Repezza y referenciado en las figuras de John William Cooke y Mario Valotta. ${ }^{21}$ La organización parece haberse disuelto tras unos pocos años de funcionamiento, por lo que sus miembros posteriormente irían quedando como militantes sueltos o integrándose a las nuevas formaciones de la izquierda peronista y marxista.

"Lina" Averna, quien había entrado a ILASA con 16 años y también integraba la "18 de marzo" y el PAR, recuerda acerca de Edith:

"Con Edith aprendimos a tener unidad, a tratar de encauzarnos como activistas y que cada una pudiera cumplir el rol que tuviese coraje de hacer. Muy buena dirigente. Ella fue la primera mujer que se plantó ante 5 o 6.000 tipos a hablar en una asamblea del Córdoba Sport. Por eso a partir de ahí se nos tenía cierto respeto, y en las marchas que había con abandono de planta siempre íbamos a la cabeza del gremio, con Edith y todo el grupo nuestro". ${ }^{22}$

El golpe que instauró la dictadura de la "Revolución Argentina" en 1966, que llegó con la intención de cerrar la crisis de hegemonía que atravesaba la Argentina desde hacía una década, terminó por el contrario convirtiéndose en aliciente de un proceso de creciente conflictividad y radicalización. En el movimiento obrero, esto se tradujo en la conformación de la CGT de los Argentinos (CGT-A) en 1968, con posiciones combativas anti-dictatoriales, y en el crecimiento de expresiones sindicales radicalizadas y clasistas. En el SMATA Córdoba, la hegemonía torrista comenzó a resquebrajarse, y entre los trabajadores se organizó una nueva lista opositora, la Lista Azul, políticamente muy heterogénea pero ligada a la CGT-A, que en la provincia tenía como principal referente a

\footnotetext{
${ }^{19}$ Respecto de Torres, en una entrevista realizada en 1997, Gladys recordaba: “Al principio no nos aceptaban porque éramos mujeres, pero después se la tuvieron que tragar. A Torres le hacíamos la guerra. Elpidio era un atorrante que transaba". En Revista Los 70, № 8 “El clasismo", 1997, p. 10.

${ }^{20}$ Cabe señalar que, si bien su incorporación a una de las listas rompía por primera vez el monopolio sindical masculino, su ubicación subalterna como Pro-Secretaria de Actas la situaba bajo la dirección del Secretario de Actas -varón- y reproducía la idea de que las mujeres tenían una especial aptitud para las tareas burocrático-administrativas como prolongación de sus capacidades domésticas.

${ }^{21}$ El documento fundacional del PAR fue "El peronismo, ¿movimiento de izquierda?", editado en Córdoba en julio de 1962. Allí, a partir de considerar que "Izquierda es sinónimo de popular, de justo, de eliminación de los privilegios, de liquidación de todas las injusticias, de rompimiento con la penetración imperialista, de extirpación de la oligarquía, de formas sociales nuevas donde el trabajador sea un ser digno y no una simple pieza del engranaje de explotación capitalista", la respuesta a la pregunta del título era categórica: “El peronismo es izquierda". A su vez, en varios números del periódico El Compañero, dirigido por Valotta, pueden encontrarse notas sobre las actividades y posiciones de la "18 de marzo" y el PAR cordobés. Ver № 19 , 30/10/1963, pp. 5-6; № 39, 24/03/1964, p. 6; № 43, 21/04/1964, p. 6; № 49, 2/06/1964, p. 6.

${ }^{22}$ Entrevista del autor a Rosalina Averna ("Lina”), Córdoba, 16/11/2018.
} 
Agustín Tosco de Luz y Fuerza, al tiempo que comenzaron a crecer nuevas agrupaciones vinculadas a las organizaciones de la nueva izquierda revolucionaria.. ${ }^{23}$ A esto se sumó la crisis de Kaiser y su compra por parte del monopolio francés Renault en 1967, que implicó una ofensiva racionalizadora en todas las plantas, incluida ILASA:

“Hubo mucha diferencia en cómo nos trataban los yanquis y cómo nos trataron después los franceses. Cambió mucho el sistema. El que estaba a cargo de ILASA con Kaiser era un gordito petiso, un filántropo, y era como que éramos las nietas nosotras. Teníamos una fiesta por año, con música y qué se yo... Era una relación distinta, lo cruzábamos, andaba ahí adentro de la fábrica charlando con una, con otra. Pero cuando llegaron los franceses, ¡miércoles!, teníamos el reloj ahí y teníamos que sacar la producción sí o sí. Fue un cambio drástico" ${ }^{24}$

El Cordobazo de 1969 fue el punto de quiebre para el movimiento obrero provincial. El 14 de mayo, ante la noticia de la derogación del "sábado inglés" por parte de la dictadura, más de 6.000 trabajadores del SMATA se reunieron en el Córdoba Sport, entre ellos las obreras de ILASA. La asamblea culminó violentamente, con represión y gases dentro del estadio y enfrentamientos callejeros. El 29, ante la convocatoria de las direcciones sindicales de la provincia, en todas las plantas afiliadas al SMATA se hizo abandono de fábrica y se marchó al centro. La represión y el asesinato de Máximo Mena desataron el estallido popular generalizado, que incluyó el enfrentamiento directo con las fuerzas policiales, la erección de barricadas, la ocupación de barrios enteros y la destrucción de símbolos del poder económico y político. Los hechos desbordaron las intenciones de Torres y de la dirigencia sindical en general, y la rebelión obrera, estudiantil y popular de Córdoba hirió de muerte al proyecto de la "Revolución Argentina", abriendo un período de ascenso de la protesta social y la radicalización política. En una de las primeras producciones académicas sobre el Cordobazo, Juan Carlos Agulla señaló que la masa de mujeres obreras de la ciudad "casi estuvo ausente" en dicha jornada, pero la reciente compilación realizada por Bibiana Fulchieri de los testimonios de mujeres que participaron del estallido, así como esta reconstrucción de la experiencia de ILASA, evidencian que también para las obreras, empleadas, militantes o simplemente habitantes de la ciudad el Cordobazo constituyó un hecho que las tuvo como protagonistas y las impactó profundamente (Agulla, 1969, pp. 16-17; Fulchieri, 2018). “Lina” Averna lo resume con claridad:

\footnotetext{
${ }^{23}$ Para una reconstrucción de este proceso, ver: Laufer (2017). Entre 1966 y 1972, a la más antigua presencia del mencionado PAR, el Partido Comunista (PC) y el Partido Obrero (Trotskista) (PO-T), se sumaron el Partido Revolucionario de los Trabajadores (PRT), el Partido Comunista Revolucionario (PCR), Política Obrera (PO), el Peronismo de Base (PB), Vanguardia Comunista (VC), El Obrero y Espartaco.

${ }^{24}$ Entrevista de Santiago García a Rosario Elena (“Onel”) en poder del autor, Córdoba, 06/2014. Rosario entró a ILASA en 1964 y fue delegada durante el período de la conducción de la Lista Marrón.
} 
“A mí me tocó hacer la punta en el abandono de tareas del 29 a las diez y media. Nos subimos a una Estanciera del SMATA y enfilamos hacia el centro de Córdoba. Recuerdo que me agarré un susto grande cuando vi en la parte trasera del auto un montón de molotov. Pudimos llegar por Colón hasta el Cinerama y allí nos enfrentamos con la policía montada. ¡A pura bolita los hacíamos retroceder! Nosotras estábamos todas juntas y me acuerdo de la alegría que teníamos, yo me animaría a decir que el Cordobazo fue un verdadero bautismo para las que nunca abandonamos la lucha".$^{25}$

Abierto el proceso de renovación de los convenios colectivos en la segunda mitad de 1969, los mecánicos reactivaron la movilización, pero ahora caracterizada por la "irrupción de las bases sobre los dirigentes" (Brennan y Gordillo, 2008, p. 111). Así, mientras Torres parecía estar en el pico de su poder, siendo reelegido en el SMATA y al mismo tiempo consagrado como Secretario General de la CGT Córdoba normalizada, por abajo se afirmaba otra tendencia. Y no solo en el SMATA: en marzo de 1970, una asamblea de trabajadores de Fiat Concord destituyó a la dirección sindical "amarilla" del SITRAC y designó una Comisión Provisoria, fijando el punto de inicio de lo que sería la experiencia del clasismo en SITRAC-SITRAM.

El 12 de mayo, una asamblea de los trabajadores de Perdriel, pasando por encima al torrismo, resolvió la ocupación de la fábrica en contra del traslado de cuatro obreros, dos de los cuales se perfilaban como delegados opositores (Laufer, 2016). Retuvieron como rehenes a 38 directivos, rodearon la planta de tanques de nafta y se prepararon para enfrentar y resistir un intento de desalojo. En ese marco, recibieron una más que significativa solidaridad:

“Una empresa menor, ILASA, también del gremio de mecánicos, pero en la cual trabajan mujeres, es la primera que se solidariza con nosotros. Fue algo muy emocionante. Siempre habíamos visto a las compañeras, incluso a veces en la calle, peleando, pero nunca habíamos visto una columna de mujeres obreras. Recuerdo que venían con una bandera argentina al frente. Esa fue la primera solidaridad que nosotros tuvimos y que, de hecho, nos daba mucha fuerza para seguir nuestro conflicto". ${ }^{26}$

La decisión de los obreros de Perdriel y la extensión de la solidaridad entre las bases del SMATA y de todo Córdoba forzó a la dictadura y a Torres a buscar una solución. Al tercer día de toma se obtuvo un triunfo contundente, con la reversión de los traslados y la elección de los delegados.

\footnotetext{
25 Testimonio de Rosalina Averna, en Fulchieri (2018, p. 43).

${ }^{26}$ Testimonio de un obrero de Perdriel, en Hechos y Protagonistas, № 1 “Salamanca”, p. 7.
} 
En ILASA y otras empresas la negociación de los convenios estaba trabada. Un comunicado del SMATA denunciaba "la incalificable actitud de la empresa ILASA, que explota a su personal con salarios de hambre y hoy se niega a reconocer un incremento justo", y detallaba:

"Cerca de trescientos trabajadores de ILASA, en su mayor parte mujeres, perciben salarios inferiores en un cincuenta por ciento de lo que gana el resto de los trabajadores industriales, pero, no obstante ello, la empresa, cuyo paquete accionario pertenece en gran medida a IKA-Renault y cuyos balances arrojan fabulosas utilidades, mantiene su intransigencia en la mesa de las tratativas para renovar el Convenio de Trabajo". ${ }^{27}$

Así, el 22 y el 27 de mayo, la totalidad del personal de la planta realizó abandonos de tareas, con asambleas en puerta de fábrica e incluso dirigiéndose masivamente hasta la planta de IKA-Renault de Santa Isabel a requerir la solidaridad del resto de los trabajadores del SMATA. 28

\section{Imagen 3. Una clara mayoría de mujeres en el abandono en ILASA}

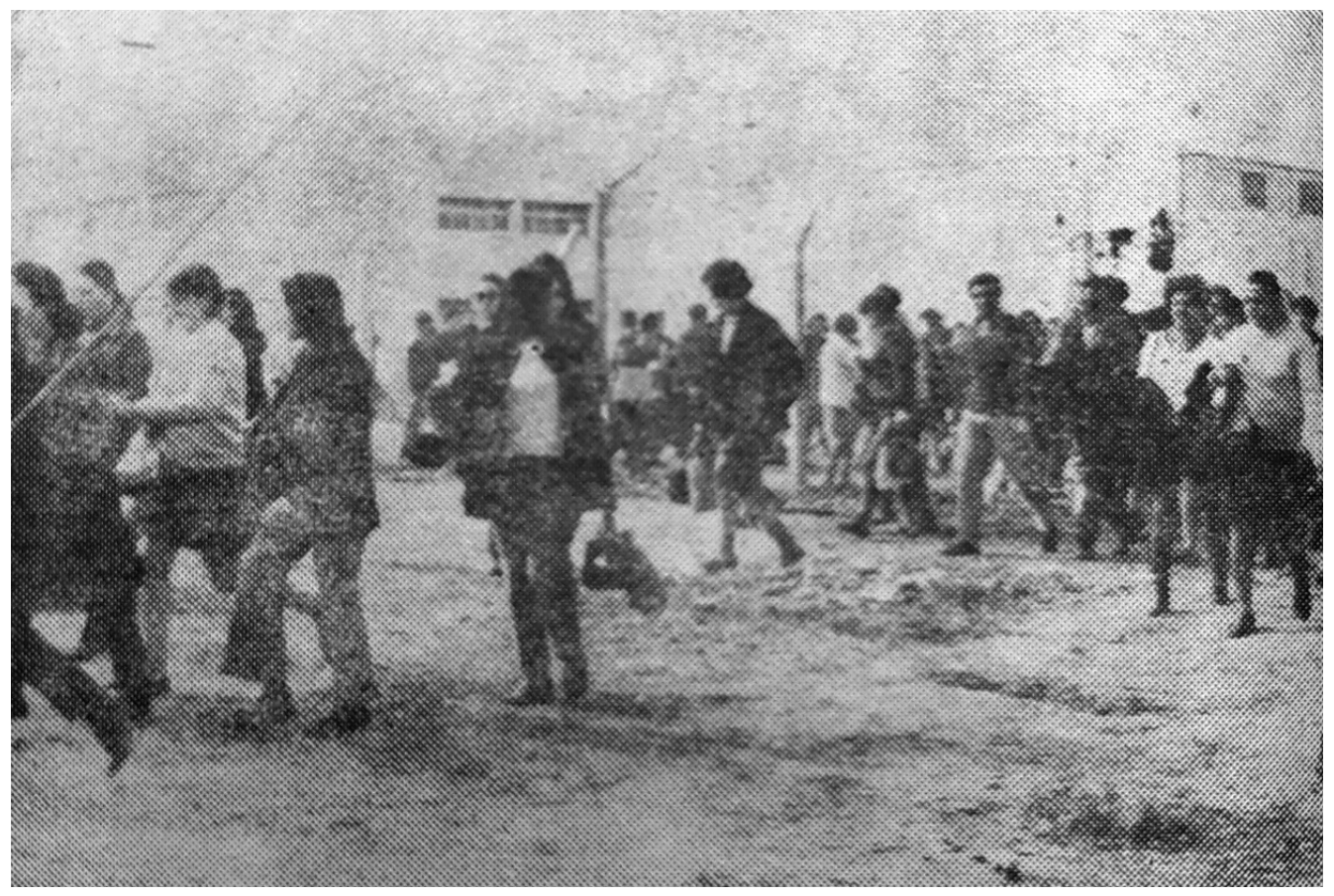

Fuente: Los Principios, 28/5/1970, p. 8.

27 "Personal de ILASA hizo abandono de la planta", Córdoba, 22/05/1970.

${ }^{28}$ Ibídem. Los Principios, 28/05/1970. 
En estas condiciones, con el antecedente de Perdriel y ante el primer aniversario del Cordobazo, el Cuerpo de Delegados del SMATA resolvió participar del acto convocado por la CGT para el 29 de mayo y llevar adelante luego un plan de ocupaciones de todas las plantas. ${ }^{29}$ La medida se mantuvo en secreto, con su organización circunscripta a los delegados y delegadas de las distintas fábricas. El 2 de junio se procedió a la ocupación simultánea de Santa Isabel, Perdriel, ILASA, Grandes Motores Diesel, Transax y Thompson Ramco. El escenario era complejo, ya que la muerte de Pedro Eugenio Aramburu en manos de Montoneros había endurecido las medidas represivas de la dictadura, que sancionó incluso la pena de muerte, pero en todas las empresas se resolvió seguir adelante. Los reclamos incluían cuestiones salariales, de categorías, de insalubridad y garantías para el funcionamiento sindical, ${ }^{30}$ pero, más allá de lo reivindicativo, la vinculación de la medida con el aniversario del Cordobazo, la crisis política de la dictadura y los repertorios de acción escogidos daban a la acción de los mecánicos un fuerte impacto político. Unos 6.000 obreros participaron en las tomas y los directivos retenidos como rehenes llegaron a 700. En cada fábrica se organizó un Comité de Ocupación y se mantuvo el estado de asamblea permanente. Se rodearon las plantas con tanques de combustible y materiales explosivos, se electrificaron las rejas exteriores, se establecieron guardias de seguridad rotativas y se prepararon las mangueras de incendio y bombas molotov para resistir la eventual represión. Al día siguiente, se sumaron las tomas de Fiat Concord, Fiat Materfer y Perkins.

En ILASA, solo el núcleo de delegados y delegadas y el activismo más cercano conocían el plan de ocupaciones: "Éramos un grupo de 10 que sabíamos que íbamos a tomar la fábrica, y el resto nadie sabía. Entonces llegó el momento, los muchachos trancaron los portones y agarramos los rehenes" cuenta "Onel". ${ }^{31}$ Tras ello, se realizó una asamblea que ratificó la medida. El pliego de reivindicaciones particular de ILASA consistía en cuatro puntos:

“1. Reestructuración del actual sistema de categorías, impidiendo la explotación de las compañeras. 2. Plena vigencia en Córdoba de la Ley 11.317 sobre instalación de guarderías infantiles en fábricas donde trabajan mujeres. 3. Plena vigencia en Córdoba de la Ley 11.595/56 respecto al trabajo de igual valor igual salario, evitando de esa manera la discriminación de la mano de obra masculina y femenina. 4. La eliminación absoluta de todo tipo de "pases internos" que se aplica a los trabajadores con fines persecutorios". ${ }^{32}$

\footnotetext{
${ }^{29}$ Para una reconstrucción y análisis del conjunto del conflicto, ver: Laufer (2019).

${ }^{30}$ Documentación e Información Laboral, № 124, junio 1970.

${ }^{31}$ Entrevista a Rosario Elena (“Onel”), op. cit.

32 "Seis plantas fabriles ocuparon ayer los afiliados del SMATA", La Voz del Interior, 03/06/1970, p. 20.
} 


\section{Imagen 4. La planta de ILASA tomada}

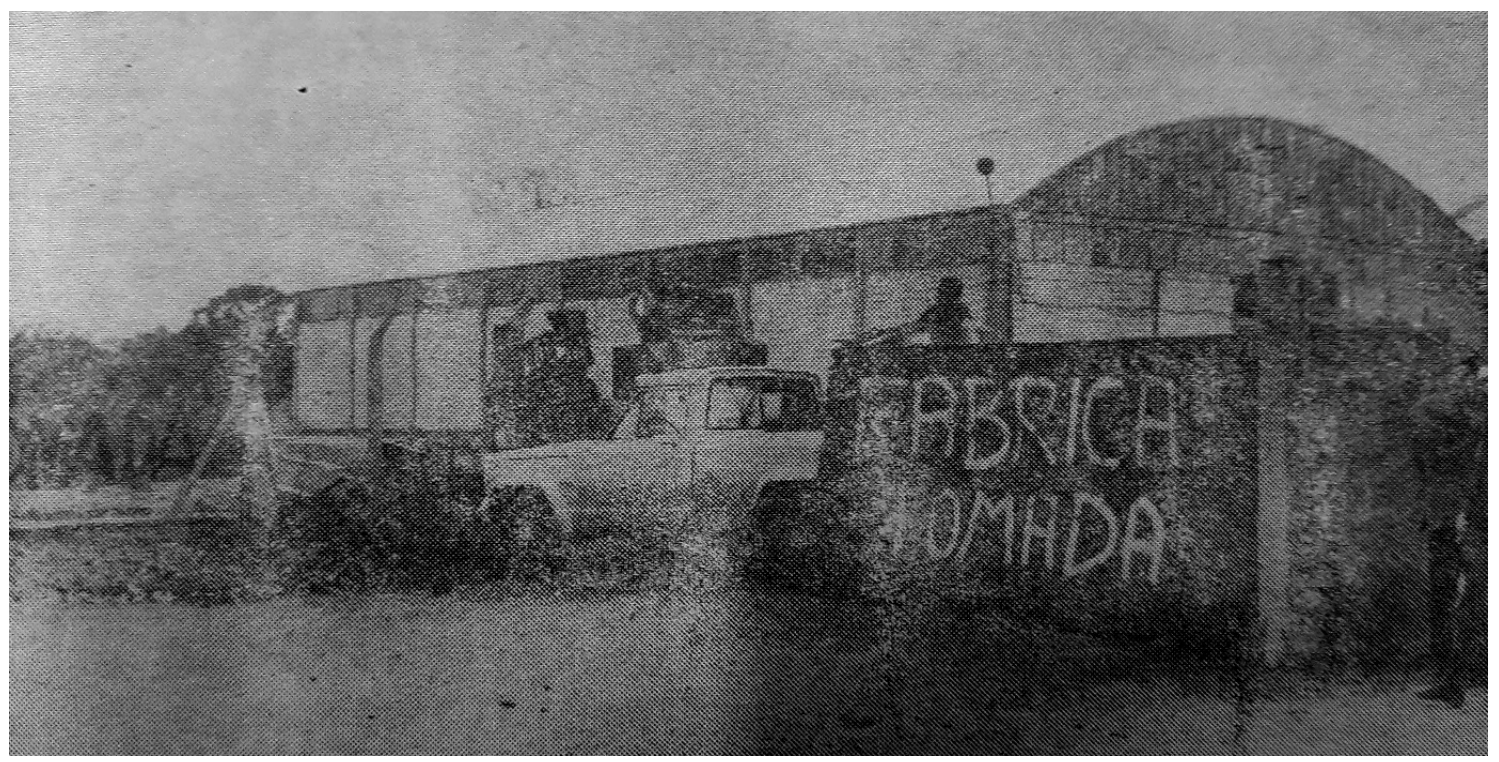

Fuente: Los Principios, 3/6/1970, p. 12.

\section{Imagen 5. La planta de ILASA tomada}

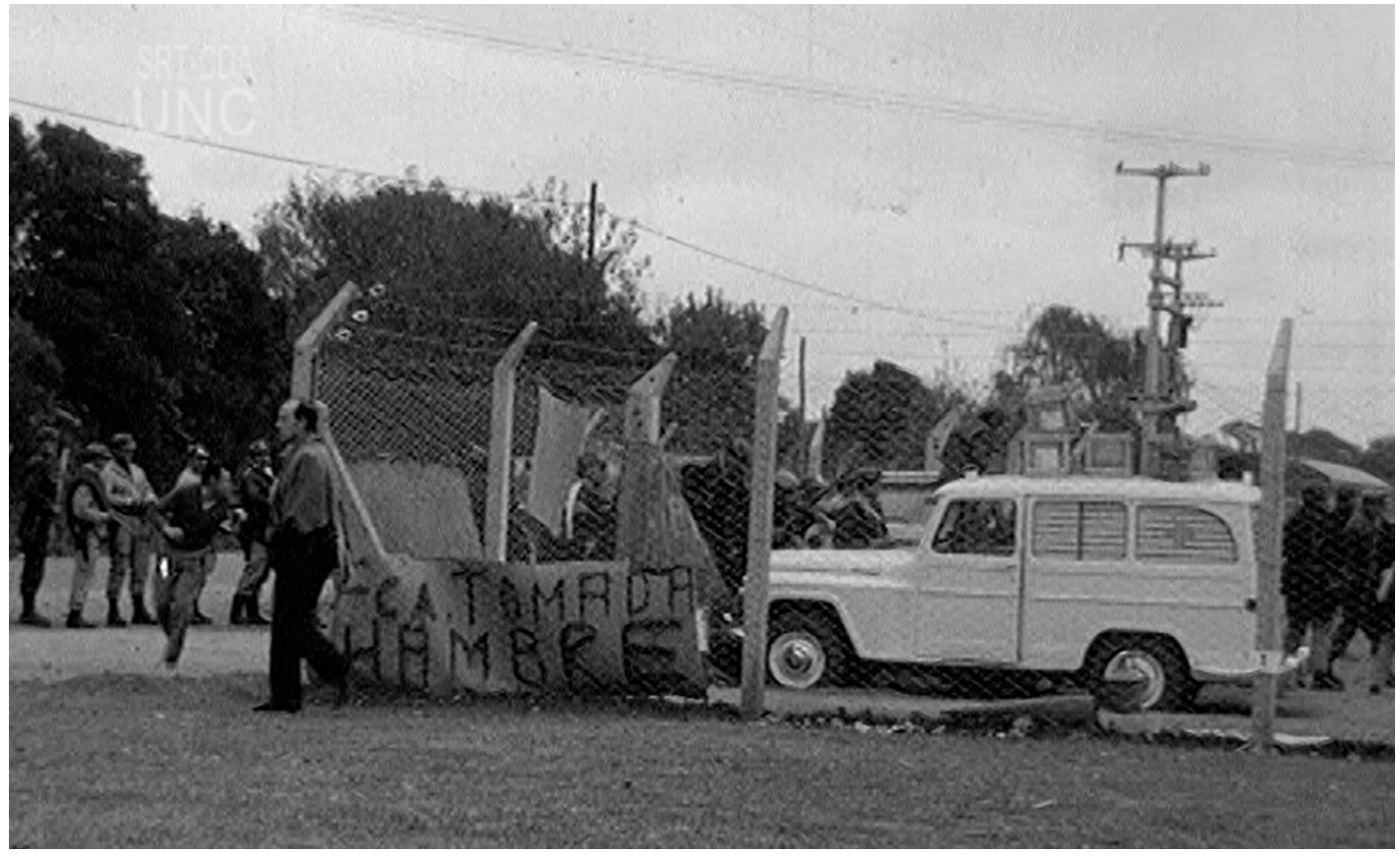

Fuente: CDA-Archivo Fílmico-UNC. Canal 10. Derechos amparados por Ley 11.723. 
Fueron retenidos 15 rehenes, se rodeó la planta con tanques de gas y, como se puede observar en las imágenes, se cruzó en las puertas de entrada un jeep de la empresa y una ambulancia con los neumáticos desinflados y grandes carteles que junto al tradicional "Fábrica tomada" incluían la palabra "Hambre", lo que daba cuenta de los bajos salarios de las obreras de la planta, en una rama industrial que era conocida por ocupar a "los trabajadores mejor pagos del país". ${ }^{33}$ A su vez, se hizo un pozo en el alambrado perimetral para el caso de tener que escapar. Solo se permitió que se retiraran las obreras que estaban enfermas, embarazadas o tenían hijos pequeños. ${ }^{34}$ Así describían los medios el panorama:

“Grupos de mujeres -que predominan en el establecimiento- trabajan en la confección de los cartelones en los que pueden leerse las consabidas leyendas alusivas a la ocupación. Algunos hombres acarrean materiales para reforzar las clausuras de los accesos mientras otros nos refieren: "resistiremos la entrada de la policía. Ahí están a la vista 24 tubos de gas de 200 litros cada uno. Se accionan mediante una mecha de autoencendido y les pegaremos fuego si se pretende desalojarnos. Tenemos nafta, maderas y gasoil en grandes cantidades y pensamos quedarnos aquí hasta que el gremio decida lo contrario". ${ }^{35}$

La toma trastocó todas las relaciones de poder y jerarquías al interior de la fábrica:

"A los rehenes no se les permitía nada, como ellos a nosotras: vos no podías hablar con las compañeras, tenías un tipo atrás tuyo que te estaba cronometrando la producción, ibas a tomar agua dos o tres veces y ya te estaba mirando el supervisor, ibas dos veces al baño y te decían '¿Qué le pasa? ¿Se siente mal?'. Entonces los encerraron a los tipos en una oficina y les llevaban comida del comedor. $\mathrm{Y}$ les dieron dos pases para que vayan al baño. Eso fue para nosotras una reivindicación total, total" ${ }^{36}$

En esas condiciones pasaron más de dos días y noches, con las obreras y obreros durmiendo entre los rollos y mazos de cables. El 4 de junio, la dictadura procedió a los desalojos comenzando por Perdriel, donde los obreros enfrentaron la represión durante casi una hora, con un saldo de 65 detenidos. Inmediatamente esto repercutió en las demás fábricas y en ILASA, que estaba muy cerca de la planta de matricería:

\footnotetext{
33 “Simultáneamente obreros del SMATA ocuparon seis fábricas”, Los Principios, 03/06/1970, p. 11.

${ }^{34}$ Aquí aparece ilustrada la fuerza de los mandatos tradicionales de género, por los cuales las mujeres con hijos quedaban excluidas de la lucha en virtud de sus prioritarias responsabilidades maternales y domésticas. A lo que se puede agregar la mácula que cargaban los embarazos por fuera de una relación matrimonial: "Había una compañera que estaba embarazada de cuatro meses, pobrecita, y no podía decirlo porque era soltera, en aquella época". Entrevista a Nidia M. Terragni, op. cit.

${ }^{35}$ Ibídem.

36 Ibídem.
} 
“Yo no sé si vino alguien de Perdriel o si alguien había salido de ILASA y había ido hasta allá, y vino desesperado a decirles a los compañeros: 'Saquen a las chicas porque en Perdriel entró la cana y los están matando'. Hacía poquito tiempo del desalojo de la Facultad de Ingeniería, que a las chicas las habían hecho de goma. Los compañeros nos protegían." 37

En el mismo sentido “Lina” agrega:

“Nosotras sabíamos que a las chicas que estaban estudiando en la universidad las habían violado, entonces dijimos 'estos se van a hacer un festín con nosotras', la policía. Entonces decidimos desalojar y no dejamos que ninguna quedara adentro". 38

Ambos testimonios dan cuenta de las tensiones y contradicciones de la incorporación de las obreras de ILASA a la acción sindical: la amenaza de la violencia sexual por parte de las fuerzas represivas como dispositivo disciplinador y una percepción compartida de que las mujeres estaban en una posición de debilidad y requerían de la protección de los obreros varones.

Así, a lo largo de la jornada, todas las fábricas fueron desalojadas voluntariamente a impulso del torrismo, excepto Santa Isabel, donde se resistió un día más. Con el plan de ocupaciones desbaratado, 400 detenidos y miles de telegramas de despido que involucraban a la mayoría del activismo y los delegados y delegadas (entre ellas las de ILASA), se abrió una nueva etapa del conflicto. El 8 de junio se inició la "huelga larga", que se prolongó mediante asambleas casi diarias. En ese marco, un grupo de "delegados y activistas de las plantas Perdriel e ILASA" emitió un comunicado en el que sostenían que "producto de una dirección reformista y claudicante, hemos sido burlados y traicionados" y denunciaban a la Comisión Directiva del SMATA por "irresponsabilidad política sindical", "aventurerismo", "debilidad" y "falta de objetivos en cuanto al real sentido de la lucha del movimiento obrero". ${ }^{39}$ En ILASA, en particular, costó mucho sostener la huelga, que tuvo altibajos:

“Habían despedido a todo el cuerpo de delegados, y la gente de a poco volvió a ir a trabajar. Yo terminé yendo también, antes de que se acabe la huelga, porque, primero y principal, ya sabía que estábamos traicionados, que Torres había negociado el despido de toda su oposición. Ya estábamos descabezadas. No quedó nadie prácticamente, el activismo quedó afuera" ${ }^{40}$

Tras casi un mes de lucha, que incluyó concentraciones, ollas populares y actos, en los que jugó un rol clave una Comisión de Acción y Lucha integrada por referentes de la

\footnotetext{
${ }^{37}$ Entrevista a Nidia M. Terragni, op. cit.

${ }^{38}$ Entrevista a Rosalina Averna, op. cit.

${ }^{39}$ Los Principios, 07/06/1970, p. 11.

${ }^{40}$ Entrevista a Nidia Terragni, op. cit.
} 
oposición sindical, y paros generales y movilizaciones convocados por la CGT cordobesa y el SMATA Nacional, el 6 de julio la huelga de los mecánicos fue finalmente quebrada. Violando la resolución de la última asamblea, el torrismo organizó a un grupo de obreros que ingresaron a Santa Isabel en colectivos de la empresa, burlando los piquetes de huelga. Rápidamente la Comisión Directiva del SMATA dio por finalizadas las medidas y en los días siguientes se abocó a negociar los despidos, que totalizaron unos 700, entre los que se encontraron la mayoría de los activistas opositores, como ambas hermanas Vera y Lina Averna.

La lucha de 1970 dejó marcas profundas entre los trabajadores mecánicos. La derrota y los despidos significaron un duro golpe para la oposición y los grupos clasistas, pero también significó el hundimiento gremial y político de Torres, que terminaría renunciando. La siguiente etapa estaría signada por la descomposición del torrismo y la reorganización de las corrientes clasistas y opositoras a través del Movimiento de Recuperación Sindical (MRS) y finalmente la Lista Marrón, que llegará a la conducción sindical en 1972. Una nueva camada de activistas de ILASA formará parte de este nuevo proceso, con obreras que habían sido una suerte de "segunda línea" durante la experiencia anterior y lograron sortear los despidos, como Nidia y "Onel”, y otras que ingresaron a la empresa en la convocatoria posterior, como Ana María Rodríguez, tres de las nuevas delegadas y referentes que tendría la Lista Marrón y el clasismo entre las mujeres automotrices de Córdoba.

\section{Palabras finales}

En este trabajo reconstruimos la experiencia fabril y sindical de las trabajadoras de la empresa de la rama automotriz ILASA entre 1964 y 1970. De este modo, nos propusimos dar un paso hacia un estudio del combativo movimiento obrero cordobés de los 60 y 70 que incluya una perspectiva de clase generizada y comience así a resquebrajar la masculinización predominante en su historia hasta el momento. La experiencia de clase se articula siempre con un sujeto genéricamente constituido. Incluso cuando estaban insertos en un mismo mundo fabril, como el de la producción automotriz cordobesa, obreros y obreras vivenciaron las condiciones de trabajo, las formas organizativas, las luchas y los procesos de radicalización con elementos diferenciales, que requieren ser restituidos para avanzar en una comprensión más compleja e integral de la historia de la clase obrera.

Las jóvenes que entraron como obreras a ILASA lo hicieron a contracorriente de lo que se acostumbraba e instituían los mandatos de género de la sociedad cordobesa de la época. Su inserción en el mundo laboral automotriz y en el SMATA, junto con la percepción, siendo aún solteras, de un salario que en términos relativos era más alto que el de otras ocupaciones "femeninas", las situó como "distintas" y "rebeldes" en comparación con otras mujeres que cumplían sin fisuras el prototipo de la "mujer doméstica". Aún así, en la fábrica la patronal también reproducía condiciones generizadas: a las obreras 
se les asignaban solo tareas simples y las categorías inferiores, lo que se traducía en salarios más bajos que los hombres de la misma planta y del resto de la industria automotriz, a lo que se sumaban otros problemas específicos como las disposiciones disciplinarias y la falta de una guardería infantil.

En estas condiciones, las obreras de ILASA se fueron incorporando a la acción sindical del SMATA bajo la dirección de un núcleo de activistas ligadas a la izquierda, convirtiéndose en uno de los más tempranos núcleos de oposición al torrismo. En un marco de alza de la conflictividad social y la radicalización política de fines de los 60 e inicios de los 70, las trabajadoras de la planta participaron en asambleas masivas, marcharon por las calles, combatieron en el Cordobazo e impulsaron la lucha por la renovación del Convenio en 1970 y la toma de la fábrica poniendo sobre la mesa una serie de puntos que hacían específicamente a la sobreexplotación que sufrían como mujeres. Su participación en la lucha obrera las incluyó dentro del colectivo de clase, trastocó las relaciones de poder en la planta -entre supervisores hombres y obreras mujeres- y permitió también comenzar a tensionar ciertos estereotipos y prescripciones de género. La simultaneidad de este proceso con los cambios sociales y culturales que en este período se estaban experimentando, deja planteado como cuestión a profundizar la pregunta de hasta qué punto las trabajadoras de ILASA fueron receptivas de las influencias de la liberación femenina y si esto estuvo vinculado con su proceso de politización y participación sindical.

La toma y la lucha de 1970 constituyeron un punto de inflexión para ILASA, así como para todos los trabajadores y trabajadoras del SMATA. Como uno de los primeros bastiones anti-torristas por izquierda, las mujeres de ILASA fueron protagonistas y parte destacada del proceso de cambio de estrategias sindicales y radicalización política que se estaba gestando en el SMATA cordobés. La siguiente camada de activistas obreras, continuando sobre las huellas precedentes, sería partícipe de la nueva etapa que llevó a la Lista Marrón y al clasismo a la conducción del sindicato.

\section{Referencias bibliográficas}

AAVV (2006). Mujeres desde el Cordobazo a nuestros días. Córdoba: Movimiento de Mujeres Córdoba.

Agulla, J. C. (1969). Diagnóstico social de una crisis: Córdoba, Mayo de 1969. Córdoba: Editel. Andújar, A. (2017). Historia social del trabajo y género en la Argentina del siglo XX: balance y perspectivas. Revista Electrónica de Fuentes y Archivos (REFA), 8, 43-59.

Baracat, E. (1972). Situación de la mujer que trabaja en la provincia de Córdoba. Ministerio de Desarrollo de la Provincia de Córdoba.

Barragán, I. y Rodríguez, F. (2013). Clase, género, politización y violencia. Los casos del Astillero Río Santiago y Propulsora Siderúrgica 1974-1975. Revista de Estudios Marítimos y Sociales, 5, 43-54. 
Barragán, I. (2014). Matilde Itzigsohn, la militancia sindical de base y la violencia. Trayectoria en una fábrica de hombres, el Astillero Río Santiago (1973-1976). Revista Amerika, 11. URL: Disponible en: http://amerika.revues.org/5661. (Descarga 20/02/2019).

Barragán, I. (2015). Mujeres trabajadoras y delegadas sindicales en un astillero de la Armada Argentina. Astillero Río Santiago (1973-1978). Revista Nomadías, 20, 227-248.

Bock, G. (1989). La historia de las mujeres y la historia del género: Aspectos de un debate internacional. Historia Social, 9, 55-77.

Brennan, J. P. (1996). El Cordobazo. Las guerras obreras en Córdoba 1955-1976. Buenos Aires: Sudamericana.

Brennan, J. P. y Gordillo, M. (2008). Córdoba rebelde. El Cordobazo, el clasismo y la movilización social. La Plata: Editorial De la Campana.

Chamorro Greca, E. (1969a). La mujer en la estructura familiar. En "La mujer argentina y latinoamericana. Memoria del VIII Curso de Temporada - Año 1967". Revista de la Universidad Nacional de Córdoba, X (1-2), 221-240.

Chamorro Greca, E. (1969b). La madre que sale a trabajar. En “La mujer argentina y latinoamericana. Memoria del VIII Curso de Temporada - Año 1967", Revista de la Universidad Nacional de Córdoba X (1-2), 241-265.

Cipolla, F. (2004). La epopeya de Kaiser-Renault, 1954-1975. Córdoba: Ediciones del Boulevard.

Cosse, I. (2009). Los nuevos prototipos femeninos en los años 60 y 70: de la mujer doméstica a la joven "liberada". En A. Andújar, D. D’Antonio, F. Gil Lozano, K. Grammático y M. L. Rosa (Comp.), De minifaldas, militancias y revoluciones. Exploraciones sobre los 70 en la Argentina (pp. 171-186). Buenos Aires: Luxemburg.

D'Antonio, D. y Viano, C. (2017). A propósito de la Historia Reciente, la Historia de las Mujeres y los estudios de género: intersecciones y desafíos. En G. Águila, L. Luciani, L. Seminara y C. Viano (Comps.), La historia reciente en Argentina. Balances de una historiografía pionera en América Latina. Buenos Aires: Imago Mundi.

Floresta, P. (2012). Conflictividad docente a comienzos de los 70 en Córdoba. LA UEPC y la participación sindical femenina. Córdoba: Editorial de la FFyH-UNC.

Fulchieri, B. (2018). El Cordobazo de las mujeres: memorias. Córdoba: Editorial Las Nuestras.

Ghigliani, P. (2018). Las mujeres trabajadoras en la industria gráfica de los años sesenta y setenta: participación sindical, agencia contenciosa y discurso de género. Trabajo y Sociedad, 31, 149-166.

Hall, C. (2013). La historia de Samuel y Jemima: Género y Cultura de la clase trabajadora en la Inglaterra del siglo XIX. Mora, 19 (2), 83-99.

Hobsbawm, E. (2007). Historia del Siglo XX. Buenos Aires: Crítica.

Gordillo, M. (1996). Córdoba en los 60. La experiencia del sindicalismo combativo. Córdoba: REUN.

Kelly Gadol, J. (1976). The social relation of the sexes: Methodological implications of Women's History. Signs, 1 (4), 809-823. 
Laufer, R. (2016). El clasismo en el SMATA Córdoba. Ocupaciones fabriles, democracia sindical e izquierda clasista: la toma de la matricería Perdriel, mayo de 1970. Estudios del Trabajo, 49, 91-121.

Laufer, R. (2017). El clasismo en el SMATA Córdoba, 1966-1972. En B. Rupar, A. Costilla y G. Galafassi (Coords.), Dirán hubo gigantes aquí. Izquierda, peronismo y clase obrera en los 60 y 70 (pp. 115-137). Buenos Aires: GEACH-UNQUI.

Laufer, R. (2019). Estrategias sindicales y desarrollo del clasismo en la Argentina de los 70. Las ocupaciones fabriles y la huelga larga del SMATA Córdoba, junio-julio de 1970. Revista Despierta, 5 (5), 47-75.

Lenguita, P. A. (2018). La rebelión de las obreras: el caso de la ocupación en Bagley entre 19741975. Ponencia presentada en el "VI Congreso de Estudios sobre el Peronismo (19432018)". Universidad Metropolitana para la Educación y el Trabajo (UMET): CABA.

McCloud, J. (2015). Del Jeep al Torino. La historia de IKA, primera planta automotriz integrada de Sudamérica. Buenos Aires: Lenguaje Claro Editora.

Mignon, C. (2014). Córdoba obrera. El sindicato en la fábrica 1968-1973. Buenos Aires: Imago Mundi.

Mitidieri, G. (2014). La huelga de Alpargatas en 1979: las nociones de lo justo en dictadura. Páginas, 12, 83-102.

Noguera, A. (2013). La participación de las mujeres en la lucha armada durante los tempranos setenta. Córdoba. 1970-1973. Taller (Segunda Época), 2 (2), 10-23.

Noguera, A. (2019). Cartografías femeninas. Un acercamiento al mundo del trabajo con perspectiva de género. Córdoba, 1960-1970. Ponencia presentada en las Jornadas "A 50 años del Cordobazo. Repensando el ciclo de protestas obreras, rebeliones populares e insurrecciones urbanas". FFyH-Universidad Nacional de Córdoba: Córdoba.

Noguera, A. (2019). Revoltosas y revolucionarias. Mujeres y militancia en la Córdoba setentista. Córdoba: Editorial de la Universidad Nacional de Córdoba.

Ortiz, M. L. (2015). Violencia y represión. Los trabajadores clasistas en Córdoba, 1969-1976 (Tesis de Doctorado en Historia). FFyL-Universidad de Buenos Aires: Buenos Aires.

Palermo, H. (2015). "Machos que se la bancan": masculinidad y disciplina fabril en la industria petrolera argentina. Desacatos, 47, 100-115.

Recchini de Lattes, Z. (1980). La participación económica femenina en la Argentina desde la segunda posguerra hasta 1970. Cuaderno del CENEP, 11. Centro de Estudios de Población: Buenos Aires.

Rodríguez, F. (2010). ¿Masculinidad clasista? Aportes a un debate abierto en el campo de la historia latinoamericana contemporánea. Ponencia presentada en "Fazendo Género 9. Diásporas, diversidades, deslocamentos". USFC: Florianópolis.

Scott, J. (1993). El género: una categoría útil para el análisis histórico. En M. C. Cangiano y L. Dubois (Comps.), De mujer a género. Teoría, interpretación y práctica feminista en las ciencias sociales (pp. 17-50). Buenos Aires: CEAL. 
114 | Rodolfo Laufer

Para citar este artículo:

Rodolfo Laufer (2019). Clase y género en la Córdoba combativa. Las obreras de ILASA y la ocupación de la fábrica en 1970. Anuario de la Escuela de Historia Virtual 16, pp. 93-114. 